\title{
Mff|codis \\ Farmasi
Poltekkes Makassa \\ PEMANFAATAN PATI SINGKONG TERGELATINASI SEBAGAI PENGIKAT TABLET ASETOSAL YANG DIBUAT DENGAN METODE KEMPA LANGSUNG
}

\author{
Utilization Of Gelatinized Cassava Starch As A Binder For Acetosal Tablets Made By Direct \\ Compression Method
}

\author{
Hesty Setiawati ${ }^{1}$, Ariyani Buang ${ }^{1}$, Rusli $^{2}$, Hendra Stevani $^{2 *}$ Ratnasari Dewi $^{2}$ \\ ${ }^{1}$ Universitas Pancasakti \\ ${ }^{2}$ Politeknik Kesehatan Kemenkes Makassar
}

*Korespondensi Email :*hendra@poltekkes-mks.ac.id

DOI: https://doi.org/10.32382/mf.v16i2.1819

\section{ABSTRACT}

Direct compression is the simplest and most efficient method of making tablets, but not all additives adopt this method. This research aims to analyze the ability of gelatinized cassava starch (Manihot utillissima) as an additive for the manufacture of tablets by direct compression using the acetosal active ingredient with a concentration of $100 \mathrm{mg}$. Furthermore, the cassava starch made from tubers (Manihot utillissima) is gelatinized by heating and then used as an additive in the manufacturing of acetosal tablets by direct compression. The results showed that the gelatinized cassava starch (Manihot utillissima) powder had good flow and compressibility properties and the acetosal acetosal tablets produced had good physical properties and solubility, therefore it was concluded that it is used as an additional ingredients in manufacturing acetosal tablets with direct compression method

Keywords : Gelatinized Cassava Starch (Manihot utillissima), Direct Compression, Asetosal

\begin{abstract}
ABSTRAK
Kempa Langsung merupakan metode pembuatan tablet yang paling sederhana dan efisien, namun tidak semua bahan tambahan tablet dapat digunakan dalam metode kempa langsung. Penelitian ini bertujuan untuk menganalisis kemampuan pati singkong (Manihot utillissima) yang tergelatinasi sebagai bahan tambahan dalam pembuatan tablet secara kempa langsung dengan menggunakan bahan aktif asetosal dengan konsentrasi $100 \mathrm{mg}$. Pati singkong dari umbi singkong (Manihot utillissima) dibuat tergelatinasi dengan pemanasan lalu digunakan sebagai bahan tambahan dalam pembuatan tablet asetosal dengan metode kempa langsung. Hasil penelitian menunjukan serbuk pati singkong (Manihot utillissima) tergelatinasi memilki sifat Alir dan kompresibilitas yang baik dan tablet Asetosal asetosal yang dihasilkan memilki sifat fisik dan kelarutan yang baik, sehingga dapat disimpulkan Pati Singkong tergelatinasi dapat dimanfaatkan sebagai bahan tambahan dalam pembuatan tablet Asetosal dengan meode kempa langsung
\end{abstract}

Kata kunci : Pati Singkong (Manihot utillissima) tergelatinasi, Kempa Langsung, Asetosal

\section{PENDAHULUAN}

Tablet merupakan sediaan farmasi dengan tingkat penggunaan yang besar, selain karena penggunaannya yang mudah dan praktis, hampir semua bahan aktif dapat dibuat menjadi tablet. Kualitas suatu tablet bergantung pada sifat fisik tablet tersebut dan bioavailibitasnya. Tablet dikatakan baik jika memiliki sifat fisik yang baik melalui uji mutu fisik dan bioavailibitasnya tercapai. Kedua faktor tersebut sangat dipengaruhi oleh metode pembuatan tablet dan bahan tambahan yang digunakan. Terdapat dua metode dalam pembuatan tablet yaitu metode granulasi dan kempa langsung. ( Lachman Leon $\underline{\mathrm{dkk}, 1994)}$
Kempa langsung digunakan untuk menyatakan proses ketika tablet dikempa langsung dari campuran serbuk aktif dan eksipien yang sesuai (termasuk pengisi, pengikat, desintegran dan lubrikan) yang akan mengalir dengan seragam ke dalam lubang kempa dan membentuk padatan yang kokoh (Charles, 2010). Suatu serbuk yang akan dikempa menjadi tablet harus memilki sedikitnya 2 syarat utama agar nantinya bisa dibentuk menjadi tablet, yaitu harus memilki kompaktibilitas yang tinggi dan mampu mengalir dengan baik, namun hanya sedikit bahan aktif dan bahan tambahan (termasuk pengikat tablet) yang memilki sifat tersebut. Saat 
ini terdapat beberapa pengikat yang sering digunakan dalam pembuatan tablet kempa langsung seperti mikrokristalisn selulosa. Namun bahan tersebut tentu saja memiliki harga yang cukup mahal sehingga tablet yang diproduksi nantinya akan memiliki harga yang mahal pula. Oleh karena itu dicari alternatif lain bahan yang dapat digunakan sebagai pengikat pada tablet yaitu pati dari singkong (Manihot utilissima).

Singkong (Manihot utilissima) merupakan salah satu varietas umbi-umbian yang tidak asing bagi penduduk Indonesia, hal ini dikarenakan keberadaannya dapat disejajarkan dengan beras dan jagung yang merupakan bahan pokok sebagian besar masyarakat Indonesia. Masyarakat Indonesia biasa mengolah singkong (Manihot utilissima) menjadi berbagai makanan olahan seperti tiwul, utri, kerupuk, tape dan getuk. Disamping itu, singkong (Manihot utilissima) juga dapat diolah menjadi tepung tapioka atau pati, yang nantinya dapat dimanfaatkan pada berbagai industri pangan dan industri kimia lainnya dan terutama dalam bidang kefarmasian sebagai bahan pembuat tablet.

Dalam pembuatan tablet, pati alam (termasuk pati singkong(Manihot utilissima)) memiliki berbagai banyak kekurangan diantaranya sifat alir dan daya kompresibilitasnya yang kurang baik sehingga sifat tersebut dapat diperbaiki dengan proses modifikasi. Modifikasi pati dapat dilakukan secara fisika misalnya dengan gelatinasi atau secara kimia dengan esterifikasi dan cross link. (Megumi, dkk, 2006). Menurut Fauziah (2014), pati singkong teresterifikasi asam stearat menghasilkan pati yang memiliki sifat alir dan kemampuan pengikatan yang baik namun sifat mengembangnya yang kurang sehingga dalam pembuatan tablet masih memerlukan penambahan bahan penghancur. (Fauziah 2014)

Salah satu cara yang dapat dilakukan untuk memodifikasi pati adalah dengan gelatinasi yaitu dengan memanaskan pati diatas suhu gelatinasinya dimana suhu gelatinasi pati singkong $52-64^{\circ} \mathrm{C}$ (Jane, J., 1995, Koswara, 2009), sehingga molekul pati akan pecah dan sifat alami pati akan berubah dan diharapkan sifat yang baru tersebut dapat dimanfaatkan untuk membuat tablet. Sehingga melalui penelitian ini akan dianalisis kemampuan pati singkong (Manihot utillissima) yang tergelatinasi dapat digunakan sebagai bahan tambahan dalam pembuatan tablet terutama secara kempa langsung dengan menggunakan bahan aktif asetosal dengan konsentrasi 100 mg

\section{METODE}

Desain, tempat dan waktu

Penelitian ini merupakan penelitian eksperiment dengan desain pre dan post test control yang dilakukan di laboratorium Farmasetika dan Teknologi Farmasi Politeknik Kesehatan Makassar selama 2 bulan.

\section{Sampel Penelitian}

Sampel pada penelitian ini adalah tablet asetosal dengan pengikat pati singkong (Manihot utilissima) tergelatinasi yang digunakan dalam pengujian mutu tablet.

\section{Langkah-Langkah Penelitian}

Alat dan Bahan yang digunakan

Alat - alat yang digunakan adalah mesin pencetak tablet, timbangan analitik, timbangan kasar, jangka sorong, Mosanto Hardness Tester, Disintegration tester, Friability tester, Hot plate dan dissolution tester.

Bahan - bahan yang digunakan adalah aqua destillata, asetosal, mikrokristalin selulosa dan pati singkong (Manihot utilissima), alkohol $96 \%$, talc, magnesium stearat, asam asetat glacial, dan natrium asetat trihidrat.

\section{Penarikan Pati Singkong (Manihot utilissima) \\ Umbi singkong (Manihot utilissima)} diambil dan dicuci lalu dihaluskan, kemudian dipisahkan antara ampas dan cairannya dengan cara pengendapan. Endapan dicuci berkali-kali dengan air suling. Endapan kemudian dikeringkan dengan cara diangin-anginkan. Pati kemudian dihaluskan dan diayak dengan pengayak 50, (Fauziah Nur,dkk, 2014)

\section{Gelatinasi pati singkong (Manihot utilissima)}

Dibuat pasta pati $10 \%$ dengan cara ditimbang pati sebanyak 10 gram lalu ditambahkan air sebanyak $20 \mathrm{ml}$ dan diaduk hingga homogen. Campuran pati dan air kemudian dituang ke dalam $80 \mathrm{ml}$ air panas dan diaduk hingga membentuk gel dan dicukupkan volumenya hingga 100 gram dengan air panas suhu $70^{\circ} \mathrm{C}$. Pasta kemudian didinginkan. Setelah itu, ditambahkan sedikit demi sedikit etanol $96 \%$ hingga membentuk endapan. Endapan tersebut kemudian dipisahkan dan dikeringkan. Selanjutnya, dihaluskan, dan diayak dengan pengayak nomor 50. (Fauziah Nur,dkk, 2014)

\section{Pengujian sifat fisik pati singkong (Manihot utilissima) tergelatinasi Uji sudut diam (angle of repose) \\ Pati tergelatinasi yang akan diujikan} dimasukkan seberat 100 gram ke dalam corong yang telah disiapkan sebelumnya, kemudian pati 
dijatuhkan di atas kertas grafik pada ketinggian $10 \mathrm{~cm}$ dari permukaan kertas lalu dihitung sudut kemiringannya dengan rumus tg $\alpha=\mathrm{h} / \mathrm{r}$, dimana $\mathrm{h}$ adalah tinggi dari kerucut serbuk dan $\mathrm{r}$ merupakan jari-jari permukaan kerucut (1/2 D). (Aulton, 2002)

\section{Rasio Haussner}

Ditimbang pati tergelatinasi 50 gram yang akan diuji, lalu dimasukkan ke dalam gelas ukur yang sesuai, dicatat volume awalnya (V0). Selanjutnya dilakukan pengetukan gelas ukur pada permukaan kayu dengan ketinggian $3 \mathrm{~cm}$ dengan interval waktu 2 detik, dicatat volume pengetukan setelah pengetukan yang ke 2, 4, 6, $8,10,12, \ldots .20$ (V20). Setelah itu dihitung BJ sebelum pengetukan, BJ nyata, dan rasio Haussner. (Aulton, 2002)

\section{Pengujian kadar air}

Ditimbang $5 \mathrm{~g}$ pati tergelatinasi lalu dimasukkan dalam cawan yang telah diketahui lalu dibiarkan selama 8 jam dalam lemari pengering pada suhu $37^{\circ} \mathrm{C}$, kemudian dihitung berat kering dari pati

\section{Pembuatan tablet \\ Formula tiap tablet}

Akan dibuat tablet dengan berat normal per tablet $300 \mathrm{mg}$ sebanyak 100 tablet sehingga total berat massa tablet yang akan dibuat $300 \mathrm{mg}$ x 100 tablet $=30.000 \mathrm{mg}(30 \mathrm{~g})$

\begin{tabular}{|l|c|c|c|}
\hline Nama bahan & Formula I & Formula II & Formula III \\
\hline Asetosal * & $10 \mathrm{~g}$ & $10 \mathrm{~g}$ & $10 \mathrm{~g}$ \\
\hline Pati tergelatinasi & $3 \mathrm{~g}$ & $6 \mathrm{~g}$ & $9 \mathrm{~g}$ \\
\hline Mikrokristalin sellulosa** & $3 \mathrm{~g}$ & $3 \mathrm{~g}$ & $3 \mathrm{~g}$ \\
\hline Talc** & $0,3 \mathrm{~g}$ & $0,3 \mathrm{~g}$ & $0,3 \mathrm{~g}$ \\
\hline Magnesium Stearat** & $0,15 \mathrm{~g}$ & $0,15 \mathrm{~g}$ & $0,15 \mathrm{~g}$ \\
\hline Lactosum** & $23,45 \mathrm{~g}$ & $20,45 \mathrm{~g}$ & $17,45 \mathrm{~g}$ \\
\hline
\end{tabular}

Keterangan Sumber

* FI ed IV 1998

** Rowe, 2009

\section{Pembuatan Tablet Asetosal}

Pembuatan tablet asetosal dibuat secara kempa langsung. Bahan yang akan digunakan ditimbang sesuai yang dibutuhkan, lalu dihaluskan, dicampur dan dikempa hingga menjadi tablet, (Charles, 2007)

\section{Pengujian Mutu Tablet \\ Keseragaman bobot}

Dua puluh tablet ditimbang lalu dihitung bobot rata-rata tiap tablet, lalu tablet tersebut ditimbang lagi satu per satu lalu dihitung penyimpangannya, tidak boleh lebih dari 2 tablet yang masing-masing bobotnya menyimpang dari bobot rata-ratanya lebih besar dari harga yang ditetapkan kolom A (7,5\%) dan tidak satupun tablet yang menyimpang bobotnya dari bobot rata-rata lebih dari yang ditetapkan dalam kolom B (15\%).(Depkes, 1979)

\section{Keseragam Ukuran}

Dua puluh tablet diukur diameter dan ketebalan tablet dengan menggunakan jangka sorong. Kecuali dinyatakan lain, diameter tablet tidak lebih dari 3 kali dan tidak kurang dari 1 1/3 tebal tablet. (Depkes, 1979)

\section{Kekerasan}

Kekerasan tablet diukur dengan menggunakan mosanto tester, kekerasan tablet berkisar antara $4 \mathrm{~kg} / \mathrm{cm} 2-8 \mathrm{~kg} / \mathrm{cm} 2$. (Aulton, 2002)

Keregasan (Aulton, 2002)

Dua puluh tablet dibebas debukan . Timbang saksama dalam neraca analitik kemudian dimasukkan ke dalam alat friabilator. Pengujian ini dilakukan selama empat menit atau 100 putaran. Keluarkan tablet dari alat, bebas debukan lagi dan ditimbang. (Aulton, 2002)

\section{Waktu hancur}

Pengujian waktu hancur menggunakan alat Desintegration tester berisi aqua destillata suhu 37oC. Masukkan 5 tablet ke dalam keranjang, turun-naikkan keranjang secara teratur 30 kali tiap menit. Tablet dinyatakan hancur jika tidak ada bagian tablet yang tertinggal di atas kasa. (Depkes, 1979)

\section{Disolusi Tablet}

\section{Pembuatan Dapar Asetat}

Media disolusi yang digunakan adalah

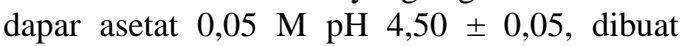
dengan menimbang natrium asetat trihidrat sebanyak 2,99 gram kemudian dicampur dengan 1,66 $\mathrm{ml}$ asam asetat glacial dan diaduk hingga 
larut lalu dicukupkan volumenya hingga $1000 \mathrm{ml}$ dengan aqua destillata. (Depkes, 1979)

\section{Pembuatan Larutan Baku}

Larutan baku dibuat dengan konsentrasi $100 \mathrm{ppm}$, dengan menimbang $100 \mathrm{mg}$ asetosal pro analisis lalu ditambahkan dalam labu ukur dengan medium disolusi dapar asetat $0,05 \mathrm{M}, \mathrm{pH}$ 4,5 dikocok hingga larut dan dicukupkan volumenya hingga $1000 \mathrm{ml}$ dengan larutan dapar asetat $0,05 \mathrm{M}$.

\section{Pembuatan Baku Kerja}

Dibuat larutan baku dengan konsentrasi 60 ppm, dengan cara mengukur larutan baku induk 100 ppm sebanyak $60 \mathrm{ml}$ lalu dimasukkan dalam labu ukur $100 \mathrm{ml}$ dan ditambahkan medium disolusi dapar asetat 0,05 M, pH 4,5 , dikocok dan dicukupkan volumenya hingga 100 $\mathrm{ml}$ dengan medium dioslusi dapar asetat 0,05 M. Dengan cara yang sama dibuat seri larutan baku konsentrasi 10, 20, 30, 40 dan 50 ppm dengan mengukur larutan baku konsentrasi 100 ppm sebanyak 10, 20, 30, 40 dan $50 \mathrm{ml}$ dan mencukupkan volumenya hingga $100 \mathrm{ml}$ dengan medium disolusi dapar asetat 0,05 $\mathrm{M}$.

\section{Penentuan $\lambda$ maksimum}

Penentuan $\lambda$ maksimum dilakukan dengan mengukur serapan larutan baku konsentrasi $60 \mathrm{ppm}$ pada panjang gelombang $200 \mathrm{~nm}$ hingga $400 \mathrm{~nm}, \lambda$ maksimum ditentukan dengan melihat panjang gelombang yang menghasilkan serapan yang paling besar. Hal yang sama dilakukan pada konsentrasi 40 ppm.

\section{Pengujian Disolusi}

Menggunakan alat tipe 2 (dayung) dengan medium dislousi $500 \mathrm{ml}$ dapar asetat 0,05 $\mathrm{M}, \mathrm{pH}$ 4,5.Media disolusi tersebut dimasukkan ke dalam wadah, alat dipasang, dan dibiarkan media disolusi hingga bersuhu $37^{\circ} \pm 0,5^{\circ}$. Dimasukkan 1 tablet ke dalam alat, dihilangkan gelembung udara dari permukaan sediaan uji dan alat segera dijalankan pada laju kecepatan 50 rpm selama 30 menit. Diambil cuplikan pada daerah pertengahan antara permukaan media disolusi dan bagian atas dari keranjang berputar. Pada menit ke 5, 10, 15 dan 30, diukur serapannya dengan spektrofotometer uv-vis pada panjang gelombang $265 \mathrm{~nm} \pm 2 \mathrm{~nm}$. Setiap pengambilan cuplikan $5,0 \mathrm{ml}$ diganti dengan larutan dapar asetat sebanyak 5,0 ml. Sampel yang diperoleh dari hasil pengujian disolusi pada menit ke 5, 10, 15 dan 30 kemudian konsentrasinya diukur pada panjang gelombang $265 \mathrm{~nm}$. Hasil yang diperoleh kemudian dihitung dengan menggunakan persamaan Kurva Baku, y $=\mathrm{a}+\mathrm{bx}$ dan konsentrasi terukur dikoreksi menggunakan persamaan Wurster.

\section{Teknik Analisis Data}

Data yang diperoleh dari hasil uji mutu tablet asetosal kemudian dibandingkan dengan persyaratan mutu dalam literature resmi dan di analisa menggunakan analisa

HASIL

Data Pengamatan Uji Granul

Tabel 1. Uji Sudut Diam dan Rasio Hausner

\begin{tabular}{lllll}
\hline \multirow{2}{*}{ Formula } & \multicolumn{4}{c}{ Pengujian Sifat Granul } \\
\cline { 2 - 5 } & Sudut diam & \multicolumn{1}{c}{ Kesimpulan } & Rasio Hausner & kesimpulan \\
\hline Formula I & 17,35 & Aliran Sangat baik & 0,7291 & Aliran baik \\
\hline Formula II & 16,73 & Aliran Sangat baik & 0,7445 & Aliran baik \\
\hline Formula III & 22,40 & Aliran baik & 0,7746 & Aliran baik \\
\hline
\end{tabular}

\section{Data pengamatan Mutu Fisik Tablet}

Tabel 1. Hasil pengukuran keseragaman bobot tablet asetosal

\begin{tabular}{llccccc}
\hline \multirow{2}{*}{ Tablet } & \multicolumn{2}{c}{ Formula I } & \multicolumn{2}{c}{ Formula II } & \multicolumn{2}{c}{ Formula III } \\
\cline { 2 - 7 } & Bobot & $\boldsymbol{\%}$ & Bobot & \% & Bobot & $\%$ \\
\hline 1 & 0,3432 & $0,82 \%$ & 0,3833 & $0,16 \%$ & 0,4134 & $0,16 \%$ \\
\hline 2 & 0,348 & $0,56 \%$ & 0,3781 & $1,20 \%$ & 0,3989 & $3,66 \%$ \\
\hline 3 & 0,3472 & $0,33 \%$ & 0,3814 & $0,33 \%$ & 0,4117 & $0,57 \%$ \\
\hline 4 & 0,3389 & $2,06 \%$ & 0,3875 & $1,26 \%$ & 0,4181 & $0,98 \%$ \\
\hline 5 & 0,3489 & $0,83 \%$ & 0,3947 & $3,14 \%$ & 0,4146 & $0,13 \%$ \\
\hline 6 & 0,3489 & $0,83 \%$ & 0,3849 & $0,58 \%$ & 0,4146 & $0,13 \%$ \\
\hline
\end{tabular}




\begin{tabular}{lllllll}
\hline 7 & 0,3456 & $0,13 \%$ & 0,3851 & $0,63 \%$ & 0,416 & $0,47 \%$ \\
\hline 8 & 0,3455 & $0,16 \%$ & 0,3873 & $1,21 \%$ & 0,4173 & $0,78 \%$ \\
\hline 9 & 0,3496 & $1,03 \%$ & 0,3746 & $2,11 \%$ & 0,405 & $2,19 \%$ \\
\hline 10 & 0,3455 & $0,16 \%$ & 0,3783 & $1,14 \%$ & 0,4287 & $3,54 \%$ \\
\hline 11 & 0,3455 & $0,16 \%$ & 0,3674 & $3,99 \%$ & 0,4078 & $1,51 \%$ \\
\hline 12 & 0,355 & $2,59 \%$ & 0,3831 & $0,11 \%$ & 0,4136 & $0,11 \%$ \\
\hline 13 & 0,3465 & $0,13 \%$ & 0,3865 & $1,00 \%$ & 0,4171 & $0,74 \%$ \\
\hline 14 & 0,3445 & $0,45 \%$ & 0,3825 & $0,05 \%$ & 0,413 & $0,25 \%$ \\
\hline 15 & 0,3456 & $0,13 \%$ & 0,3803 & $0,62 \%$ & 0,4105 & $0,86 \%$ \\
\hline 16 & 0,3422 & $1,11 \%$ & 0,3895 & $1,78 \%$ & 0,4194 & $1,29 \%$ \\
\hline 17 & 0,3456 & $0,13 \%$ & 0,3861 & $0,89 \%$ & 0,4166 & $0,62 \%$ \\
\hline 18 & 0,3455 & $0,16 \%$ & 0,3824 & $0,07 \%$ & 0,4128 & $0,30 \%$ \\
\hline 19 & 0,344 & $0,59 \%$ & 0,3791 & $0,94 \%$ & 0,4201 & $1,46 \%$ \\
\hline 20 & 0,3452 & $0,24 \%$ & 0,3815 & $0,31 \%$ & 0,4118 & $0,54 \%$ \\
\hline Rata-rata & $\mathbf{0 , 3 4 6 0 4 5}$ & $\mathbf{0 , 3 8 2 8 5}$ & $\mathbf{0 , 4 1 4 0 5}$ \\
\hline $\begin{array}{c}\text { Standar } \\
\text { deviasi }\end{array}$ & $\mathbf{0 , 0 0 3 2 2 4}$ & $\mathbf{0 , 0 0 5 7 7 5}$ & $\mathbf{0 , 0 0 6 0 8 7}$ \\
\hline
\end{tabular}

Persyaratan keseragaman bobot untuk tablet dengan berat lebih dari $300 \mathrm{mg}$ adalah "Tidak boleh lebih dari 2 tablet yang bobotnya menyimpang dari $5 \%$ dan tidak ada satupun tablet yang menyimpang bobotnya dari 10\%", dari hasil penelitian nampak bahwa semua tablet memenuhi persyaratan keseragaman bobot.

Tabel 2. Hasil pengukuran kekerasan tablet asetosal

\begin{tabular}{cccc}
\hline & \multicolumn{4}{c}{ KEKERASAN (kg/cm2) } \\
\cline { 2 - 4 } Tablet & Formula I & Formula II & Formula III \\
\hline 1 & 6 & 8 & 6 \\
\hline 2 & 5 & 5 & 5 \\
\hline 3 & 4 & 5 & 7 \\
\hline 4 & 5 & 5 & 6 \\
\hline 5 & 6 & 8 & 8 \\
\hline 6 & 4 & 5 & 5 \\
\hline rata-rata & $\mathbf{5 , 0 0}$ & $\mathbf{6 , 0 0}$ & $\mathbf{6 , 1 7}$ \\
\hline
\end{tabular}

Dari data terlihat bahwa semua formula tablet memilki kekerasan yang memenuhi persyaratan yaitu kekerasan tablet rata-rata berkisar antara $4-8 \mathrm{~kg} / \mathrm{cm} 2$

Tabel 3. Hasil pengukuran Friability (keausan) tablet asetosal

\begin{tabular}{llll}
\hline \multirow{2}{*}{ Pengujian } & \multicolumn{3}{c}{ Berat (gram) } \\
\cline { 2 - 4 } & \multicolumn{1}{c}{ Formula I } & Formula II & Formula III \\
\hline Sebelum & 6,1923 & 7,1244 & 8,3521 \\
\hline sesudah & 6,1585 & 7,112 & 8,3156 \\
\hline \% penyimpangan & $0,55 \%$ & $0,17 \%$ & $0,44 \%$ \\
\hline
\end{tabular}

Dari data terlihat bahwa semua formula tablet memilki sifat keauasan yang memenuhi persyaratan yaitu 
kurang dari $1 \%$

Tabel 4. Hasil pengukuran waktu hancur tablet asetosal

\begin{tabular}{lc}
\hline \multicolumn{1}{c}{ Tablet } & $\begin{array}{c}\text { Waktu hancur } \\
\text { (detik) }\end{array}$ \\
\hline Formula I & 13 \\
\hline Formula II & 20 \\
\hline Formula III & 41 \\
\hline
\end{tabular}

Dari data terlihat bahwa semua formula tablet memilki waktu hancur yang memenuhi persyaratan yaitu kurang dari 15 menit

\section{Data Uji disolusi}

Tabel 5. Penentuan kadar asetosal dalam bulk granul tablet

\begin{tabular}{ccccccc}
\hline \multirow{2}{*}{ cuplikan } & \multicolumn{5}{c}{ Kadar dalam (mg) } \\
\cline { 2 - 7 } & $\begin{array}{c}\text { Ferat } \\
\text { sampel }\end{array}$ & Kadar & $\begin{array}{c}\text { Berat } \\
\text { sampel }\end{array}$ & Kadar & $\begin{array}{c}\text { Ferat } \\
\text { sampel }\end{array}$ & Kadar \\
\hline 1 & 0,2991 & 0,239 & 0,2990 & 0,2300 & 0,2973 & 0,220 \\
\hline 2 & 0,3004 & 0,240 & 0,2992 & 0,2302 & 0,3004 & 0,223 \\
\hline 3 & 0,3002 & 0,240 & 0,2991 & 0,2301 & 0,2996 & 0,222 \\
\hline Rata-rata & 0,2999 & 0,2399 & 0,2991 & 0,2301 & 0,2991 & 0,222 \\
\hline
\end{tabular}

Tabel 6. Hasil perhitungan kadar asetosal

\begin{tabular}{cccc}
\hline \multirow{2}{*}{ Menit } & \multicolumn{3}{c}{ Disolusi (mg) } \\
\cline { 2 - 4 } & Formula I & Formula II & Formula III \\
\hline 5 & 183,88 & 224,64 & 277,2 \\
\hline 15 & 284,92 & 280,88 & 289,64 \\
\hline 30 & 292,04 & 287,32 & 296,6 \\
\hline $\begin{array}{c}\text { \% terlarut setelah 30 } \\
\text { menit }\end{array}$ & $\mathbf{9 7 , 3 4 \%}$ & $\mathbf{9 5 , 7 7 \%}$ & $\mathbf{9 8 , 8 7 \%}$ \\
\hline
\end{tabular}

Tabel 7. Hasil perhitungan Effisiensi Disolusi tablet asetosal

\begin{tabular}{cccc}
\hline \multirow{2}{*}{ Menit } & \multicolumn{3}{c}{ AUC } \\
\cline { 2 - 4 } & Formula I & Formula II & Formula III \\
\hline 5 & 459,7 & 561,6 & 693 \\
\hline 15 & 2344 & 2527,6 & 2834,2 \\
\hline 30 & 4327,2 & 4261,5 & 4396,8 \\
\hline Total AUC & 7130,9 & 7350,7 & 7924 \\
\hline Efisiensi disolusi & $86,58 \%$ & $83.1 \%$ & $87.44 \%$ \\
\hline
\end{tabular}

\section{PEMBAHASAN}

Penelitian ini bertujuan untuk mengetahui kemampuan pati tergelatinasi sebagai bahan pengikat pada tablet asetosal yang dibuat dengan metode kempa langsung. Pati tergelatinasi adalah pati yang mengalami perubahan sifat setelah dipanaskan diatas suhu gelatinasinya, dimana suhu gelatinasi pati singkong $52-64^{\circ} \mathrm{C}$.

Dalam penelitian ini digunakan pati singkong (Manihot utilissima) yang terlebih dahulu digelatinasi dengan memanaskan campuran pati dan air dalam konsentrasi $20 \%$ pada suhu diatas $70^{\circ} \mathrm{C}$, pati yang dihasilkan 
kemudian didinginkan lalu ditambahkan etanol 96\% untuk mengendapkan pati yang terbentuk, endapan pati kemudian di keringkan dalam oven pada suhu $70^{\circ} \mathrm{C}$ hingga kering, pati yang kering kemudian di haluskan dan diayak dengan menggunakan pengayak no 45, serbuk yang leawat dengan pengayak no 45 kemudian diayak kembali dengan menggunakan pengayak no 50, pati yang tertahan dengan pengayak no 50 kemudian dipisahakan dan digunakan untuk membuat tablet

Dari hasil pengujian keseragaman bobot tablet didapatkan bahwa semua formula tablet memenuhi persyaratan keseragaman bobot karena tidak ada satupun tablet yang menyimpang dari bobot rata-ratanya lebih dari $5 \%$ dan 10\% (DepKes 1994), dan untuk mengetahui homogenitas data tersebut dapat dihitung dengan standart deviasi. Standart deviasi adalah nilai yang menunjukan homogenitas dari suatu data, SD dengan nilai 0 (nol) menunjukan data yang homogen atau tidak ada perbedaan antar bobot tablet satu dengan lainnya, semakin nilainya menjauhi 0 menunjukan semakin tidak homogen bobot tablet tersebut, bila dilihat dari standart deviasinya (SD) maka tablet formula I memilki SD yang paling kecil yaitu 0,003 bila dibandingkan dengan formula II $(0,005)$ dan formula III $(0,006)$, sehingga dapat disimpulkan tablet formula I memiliki keseragaman bobot yang paling bagus. Keseragaman bobot tablet dipengaruhi oleh sifat alir dari granul tablet dan semakin bagus sifat alir granul tablet maka aliran granul yang masuk ke dalam lubang dies akan seragam sehingga jumlah granul yang masuk akan selalu sama dan pada akhirnya bobot tablet akan seragam. Bobot tablet yang seragam akan mengahsilkan tablet yang memilki kandungan bahan aktif yang seragam sehingga efek yang ditimbulkan juga akan seragam.

Dari uji kekerasan diperoleh hasil tablet formula satu memilki kekerasan rata-rata 5,0, tablet formula II 6,0 dan tablet formula III sebesar $6,17 \mathrm{~kg} / \mathrm{cm}^{2}$, semua tablet memenuhi persyaratan kekerasan yaitu berkisar $4-8$ $\mathrm{kg} / \mathrm{cm} 2$. Sedangkan dari uji keausan tablet diperoleh hasil tablet formula I $0,55 \%$, formula II $0,17 \%$ dan formula III sebesar $0,44 \%$, berdasarkan hasil uji keausan terlihat bahwa semua tablet memenuhi persyaratan uji keausan yaitu kurang dari $1 \%$.

Kekerasan dan keausan dari tablet menunjukan ketahanan tablet terhadap tekanan dan goncongan selama fase pembuatan, transportasi hingga sampai ditangan konsumen. Kekerasan dan keausan tablet sangat dipengaruhi oleh tekanan dari mesin pencetak tablet dan kemampuan bahan pengikat dalam hal ini adalah pati tergelatinasi. Dalam penelitian ini digunakan mesin pencetak tablet manual dengan tekananan yang umum digunakan dalam membuat tablet (tidak terlalu kuat dan juga tidak terlalu lemah), sehingga faktor mesin pencetak tablet dapat diabaikan sehingga kekerasan tablet hanya dipengaruhi oleh kekuatan dari bahan pengikat. Selaian itu didalam penelitian ini pula tidak digunakan bahan penghancur, karena sebagain besar bahan penghancur yang ada memiliki kemampuan mengikat sehingga walaupun dalam konsentrasi kecil bisa menimbulkan bias dalam hasil penelitian.

Berdasarkan hasil penelitian menunjukan semua tablet memenuhi persyaratan kekerasan dan keausan sehingga dapat disimpulkan bahwa pati tergelatinasi dapat digunakan sebagai bahan pengikat pada tablet, dan dari penelitian ini pula juga terlihat bahwa semakin tinggi konsentrasi dari bahan pengikat yaitu formula III maka semakin tinggi pula kekerasan tablet yang dihasilkan namun dari sisi keausan tablet tidak nampak ada perubahan keausan tablet bila konsentrasi bahan pengikat ditingkatkan, malahan dari data terlihat bahwa keausan yang terkecil diperoleh dari formula II.

Berdasarkan uji waktu hancur tablet terlihat bahwa formula I memilki waktu hancur 13 detik, formula II 20 detik dan formula III 41 detik. Data ini menunjukan waktu hancur semua formula tablet memenuhi persyaratan yaitu kurang dari 15 menit. Waktu hancur yang cepat akan memberikan efek yang relatif lebih cepat pula. Waktu hancur dipengaruhi oleh kekerasan tablet dan bahan penghancur yang digunakan. Semakin keras tablet maka waktu hancur akan semakin lama, dan semakin banyak bahan penghancurnya maka waktu hancur tablet juga akan semakin cepat. Dari data terlihat bahwa formula III memilki waktu hancur yang paling lama dikarenakan kekerasan tablet formula III juga yang paling keras. Selain itu dari hasil penelitian ini juga menunjukan bahwa tablet yang dibuat dengan pati gelatinasi tidak perlu penambahan bahan penghancur dikarenakan waktu hancur tablet yang dihasilkan sudah sangat cepat, bahkan waktu hancur tersebut mendekati waktu hancur tablet Fast Desintegration tablet (FDT) yaitu kurang dari 10 detik. (Aulton,2002)

Dari hasil pengujian disolusi formula I memilki kadar asetosal terlarut sebesar 97,34 \%, formula II $95,77 \%$ dan formula IIII sebesar $98,87 \%$, dari data ini dapat disimpulkan ketiga formula memenuhi persyaratan uji disolusi dimana menurut Farmakope Indonesia ed.IV, kadar asetosal terlarut setelah 30 menit tidak boleh kurang dari $80 \%$, untuk mengetahui 
perbedaan kemampuan disolusi dari ketiga formula tablet dilakukan dengan menentukan efisiensi disolusi menggunakan persamaan dalam menghitung nilai AUC. Dari hasil effiensi disolusi diperoleh data formula I ED sebesar $85,58 \%$, formula II $83,1 \%$ dan formula III $87,44 \%$, nilai ED yang tinggi menunjukan kecepatan disolusi yang paling tinggi pula, sehingga dapat disimpulkan formula III memilki kecepatan disolusi yang paling tinggi. Semakin cepat suatu zat aktif terlepas dari bentuk sediaannya dan kemudian melarut maka akan semakin cepat pula efek yang ditimbulkan

Dalam penelitian ini masih terdapat beberapa hal yang mungkin mempengaruhi hasil penelitian diantaranya penggunaan Mikrokristalin selulosa, yang dapat berperan sebagai bahan pengikat, pengisi dan penghancur (Rowe, 2009), namun dengan konsentrasi yang kecil yang digunakan dalam formula, maka kami beranggapan konsentrasi tersebut terlalu kecil untuk mempengaruhi hasil penelitian, tapi sebaiknya dalam penelitian yang selanjutnya hanya menggunakan pati singkong yang tergelatinasi tanpa menggunakan bahan-bahan lain yang dapat mempengaruhi hasil akhir

\section{KESIMPULAN}

Dari hasil penelitian dan pembahasan dapat ditarik kesimpulan pati singkong tergelatinasi dengan ukuran partikel 45/50 dapat digunakan sebagai bahan pengikat tablet asetosal yang dibuat dengan metode kempa langsung dimana semakin tinggi konsentrasi pati singkong tergelatinasi dengan ukuran partikel 45/50 maka semakin keras tablet yang dihasilkan, semakin lama waktu hancur tablet namun semakin tinggi kelarutan dari asetosal dalam tablet

\section{SARAN}

Dari hasil penelitian ini kami dapat sarankan untuk mencoba bahan aktif bahan aktif lain yang memiliki sifat yang berbeda dan sebaiknya dilakukan standarisi kandungan amilosa dan amilopectin dalam pati singkong tergelatinasi

\section{DAFTAR PUSTAKA}

Charles JP, 2007, Teknologi Farmasi Sediaan Tablet Dasar-dasar Praktis, EGC, Bandung

Depkes, 1979, Farmakope Indonesia, Edisi III, Direktorat Jenderal Pengawasan Obat dan Makanan, Jakarta

Depkes, 1994, Farmakope Indonesia, Edisi IV, Direktorat Jenderal Pengawasan Obat dan Makanan, Jakarta.
Fauziah Nur,Dkk 2014. Esterifikasi Pati Singkong dengan Asam Sterat sebagai Bahan Penambah Tablet Theophyllin Kempa Langsung. KTI Jurusan Farmasi Poltekkes Makassar.

Jane, J., 1995, Starch Properties, Modifications, and Application, Journal of Macromolecular Science

Koswara, 2009, Teknologi Modifikasi Pati, eBook Pangan.com.

Lachman Leon dkk,1994, Teori dan Praktek Industri, edisi III, UIP, Jakarta

Megumi, V.H., Tomoko, M., Naofumi, M., 2006, Recent Advances in Application of Modified Starches for Breadmaking, Elsevier Journal 17:

Aulton, 2002, The Science of Dosage Form Design Second Edition, Churchill Livingstone London

Rowe, C.R., Sheskey, PJ., Quinn, ME., 2009, Handbook of Pharmaceutical Excipients Sixth Edition, Pharmaceutical Press, London

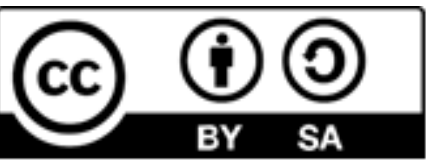

